\title{
Study of the influence of magnetized ferromagnetic additives on the processes of cement hydration
}

\author{
Serhiy Sakhno ${ }^{1, *}$, Lyudmyla Yanova $^{2}$, Olena Pischikova ${ }^{2}$, Yevhen Liulchenko ${ }^{1}$, and Tetiana Sergiienko ${ }^{3}$ \\ ${ }^{1}$ Kryvyi Rih National University, Civil Engineering Faculty, 11 Vitalii Matusevych Str., Kryvyi Rih, 50027, Ukraine \\ ${ }^{2}$ Kryvyi Rih National University, Mining and Metallurgical Faculty, 11 Vitalii Matusevych Str., Kryvyi Rih, 50027, Ukraine \\ ${ }^{3}$ Sergiienko LLC 2215 Cropsey Ave D4, Brooklyn, NY 11214, USA.
}

\begin{abstract}
One of the essential tasks for a sustainable future is to reduce harmful emissions into the atmosphere significantly. Cement production is the world's largest industrial carbon pollutant, accounting for $8 \%$ of global emissions. More than 2.2 gigatons of carbon dioxide are emitted into the atmosphere every year. Therefore, reducing the energy intensity of products and reducing the number of harmful emissions in cement production is becoming critical. One strategy to reduce cement production emissions is to reduce the most energy-consuming component in cement - clinker. In this case, various activation methods are used for maintaining the same level of cement activity. One of these methods is the impact on the hardening binder with magnetic fields. The paper presented a study of hydration processes of blast-furnace cement activated by a magnetized ferromagnetic additive. The work established that the introduction of pre-magnetized ferromagnetic dust into blast-furnace cement composition has an activating effect on binder hydration. It shows that activation occurs both in the initial and long periods of hardening. The nature of the mutual influence of the components of the hydration system alite-lime-slag in a modified binder was revealed. The investigation determined that the ferromagnetic additive, intensifying the process of slag hardening, increases the proportion of hydrated slag by 1.5-2 times. It was revealed that the formation of the ettringite framework in the modified binder's gel is completed within one day. It is shown that in the subsequent periods, hydration of aluminates occurs mainly due to the formation of tricalcium aluminate hexahydrate $\left(\mathrm{C}_{3} \mathrm{AH}_{6}\right)$, which excludes destructive processes in the late periods of binder hardening. It has been established that under the action of a ferromagnetic additive, the degree of crystallization of hydro silicates in the modified binder increases.
\end{abstract}

\section{The problem and its relationship with scientific and practical tasks}

Cement is one of the essential building materials. More than 4100000 tons of cement are produced annually globally [1], and $\mathrm{CO}_{2}$ emissions during its production are $6.5 \%$ of the global emissions or more than 2.2 gigatons of carbon dioxide per year [2,3]. In the foreseeable future, there are no prerequisites for reducing the need for cement. Therefore, reducing its products' energy intensity and reducing the number of harmful emissions is becoming increasingly important. One way to reduce cement production emissions is to introduce production waste into their composition, including granulated blastfurnace slags.

The introduction of slags makes it possible to combine a decrease in the proportion of clinker in cement with production waste disposal. However, the introduction of mineral additives, as a rule, leads to a decrease in cement activity [4]. Therefore, the proportion of active mineral additives in cement is limited. A further increase in active mineral additives' share-production waste is achieved through various cement activation methods. One of these methods is the impact on the hardening binder with magnetic fields.

\section{Analysis of research and publications}

In [5], it is noted that magnetic fields significantly affect the spin dynamics and control the spin multiplicity of radical pairs. The electron paramagnetic resonance method made it possible to determine that cement is a paramagnetic substance and that cement hardening occurs due to paramagnetic centers' recombination [5-10]. Thus, the possibility of the influence of magnetic fields on binders' hydration processes has been proved.

Traditional methods of exposure to magnetic fields on hardening cement are short-term and therefore do not lead to significant and stable results. It was proposed in works [11] to use finely dispersed magnetized ferromagnetic additives to activate blast-furnace cement. As such an additive in the research, we used fine dust - waste from the metallurgical industry. In [12], the influence of the

* Corresponding author: budfac@gmail.com 
additive's magnetic and dispersed properties on the activation effect was studied. Obtained in [12], dependences of cement strength on magnetization and particle dispersity and the additive small proportion (up to $2 \%$ ) led to the conclusion that the activation effect is not due to the filler or pozzolanic effect but due to the effect of magnetic fields. Still, the impact of long-term magnetic fields on the processes of cement hydration was not considered yet. Therefore, this work set the task to study the changes in cement hydration and structure formation processes that appear under long-term magnetic impacts.

\section{Formulation of the problem}

Studies of the hydration products of ordinary and modified by additive EN 197-1-CEM III/A $32.5 \mathrm{~N}$ cement were carried out to study the processes of hydration and structure formation of cement with premagnetized ferromagnetic dust. The research was carried out by analyzing the binder's hydration products by infrared spectrometry, thermogravimetry, X-ray phase analysis, and electron microscopy.

We have studied the original astringent and hydrated samples at 1, 3, 7, 28, and 90 days. As a magnetized ferromagnetic additive, the dust of the electrostatic precipitators of the sinter production was used. The additive was introduced in an amount of $2 \%$ of the weight of the cement.

The studies EN 197-1-CEM III/A 32.5 N cement components chemical composition are shown in Tables 13.

Table 1. The chemical composition of the cement clinker.

\begin{tabular}{c|c}
\hline Components & Content, \% \\
\hline $\mathrm{SiO}_{2}$ & 21.80 \\
\hline $\mathrm{Al}_{2} \mathrm{O}_{3}$ & 6.04 \\
\hline $\mathrm{Fe}_{2} \mathrm{O}_{3}$ & 2.54 \\
\hline $\mathrm{CaO}$ & 62,72 \\
\hline others & 6.90 \\
\hline
\end{tabular}

The quantitative and phase composition of the cement clinker is shown in Table 2.

Table 2. The quantitative and phase composition of the cement clinker.

\begin{tabular}{c|c}
\hline Components & Content, \% \\
\hline Alit & 57.27 \\
\hline Belit & 19.29 \\
\hline Aluminate & 8.72 \\
\hline Alumoferrite & 7.81 \\
\hline Other & 6.90 \\
\hline
\end{tabular}

The chemical composition of the granulated blastfurnace slag used in the CEM III/A cement used in the studies shown in Table 3.
Table 3. The chemical composition of the granulated blast furnace slag

\begin{tabular}{c|c}
\hline Components & Content, $\%$ \\
\hline $\mathrm{SiO}_{2}$ & 38.24 \\
\hline $\mathrm{Al}_{2} \mathrm{O}_{3}$ & 7.76 \\
\hline $\mathrm{Fe}_{2} \mathrm{O}_{3}$ & 0.27 \\
\hline $\mathrm{MnO}$ & 0.87 \\
\hline $\mathrm{CaO}$ & 47.02 \\
\hline $\mathrm{MgO}$ & 4.93 \\
\hline $\mathrm{SO}_{3}$ & 0.12 \\
\hline $\mathrm{TiO}_{2}$ & 0.24 \\
\hline$\Sigma$ & 99.36 \\
\hline
\end{tabular}

The chemical composition of the dust of the sinter machine is shown in Table 4.

Table 4. The chemical composition of the dust of the sinter machine.

\begin{tabular}{c|c}
\hline Components & Content, $\%$ \\
\hline $\mathrm{FeO}$ & $9-19$ \\
\hline $\mathrm{Fe}_{2} \mathrm{O}_{3}$ & $45-60$ \\
\hline $\mathrm{SiO}_{2}$ & $6.5-10$ \\
\hline $\mathrm{Al}_{2} \mathrm{O}_{3}$ & $0.5-1.5$ \\
\hline $\mathrm{CaO}$ & $6.3-9$ \\
\hline $\mathrm{MgO}$ & $0.5-1.5$ \\
\hline $\mathrm{MnO}$ & $0.2-0.3$ \\
\hline $\mathrm{P}_{2} \mathrm{O}_{5}$ & $0.03-0.05$ \\
\hline $\mathrm{S}$ & $0.2-0.5$ \\
\hline
\end{tabular}

The data obtained from the research made it possible to carry out a quantitative analysis of the kinetics of hydration of the main components of binders and identify the factors affecting structure formation processes.

\section{Statement of material and results}

The imposition of weak magnetic fields on a binder during grinding and subsequent storage can affect the cement structure's defectiveness [13-16], significantly affecting its activity [17-19]. Weak magnetic fields decreasing the probability of recombination of dissociated water molecules and increase the concentration of $\mathrm{H}_{3} \mathrm{O}+$ and $\mathrm{OH}$ - ions, thereby increasing the chemical activity of water concerning the binder [17]. Having a double effect on the mixing water and the binder itself - the magnetic fields induced by the ferromagnetic additive should change the cement's structure-forming components' strength and affect the cement's strength characteristics stone.

In the early stages, the dynamics of the formation of calcium aluminates significantly affect structure formation. Analysis of the IR spectrum (Fig. 1) in the range of $515-490 \mathrm{~cm}^{-1}$ made it possible to obtain a quantitative characteristic of calcium aluminates' 
hydration processes in control and modified binders (Fig. 2). The content of non-hydrated calcium aluminates in the modified cement stone-aged 1-28 days is $1.5-2$ times less than in the control sample, and at the age of 90 days, it is four times less than in the control sample.

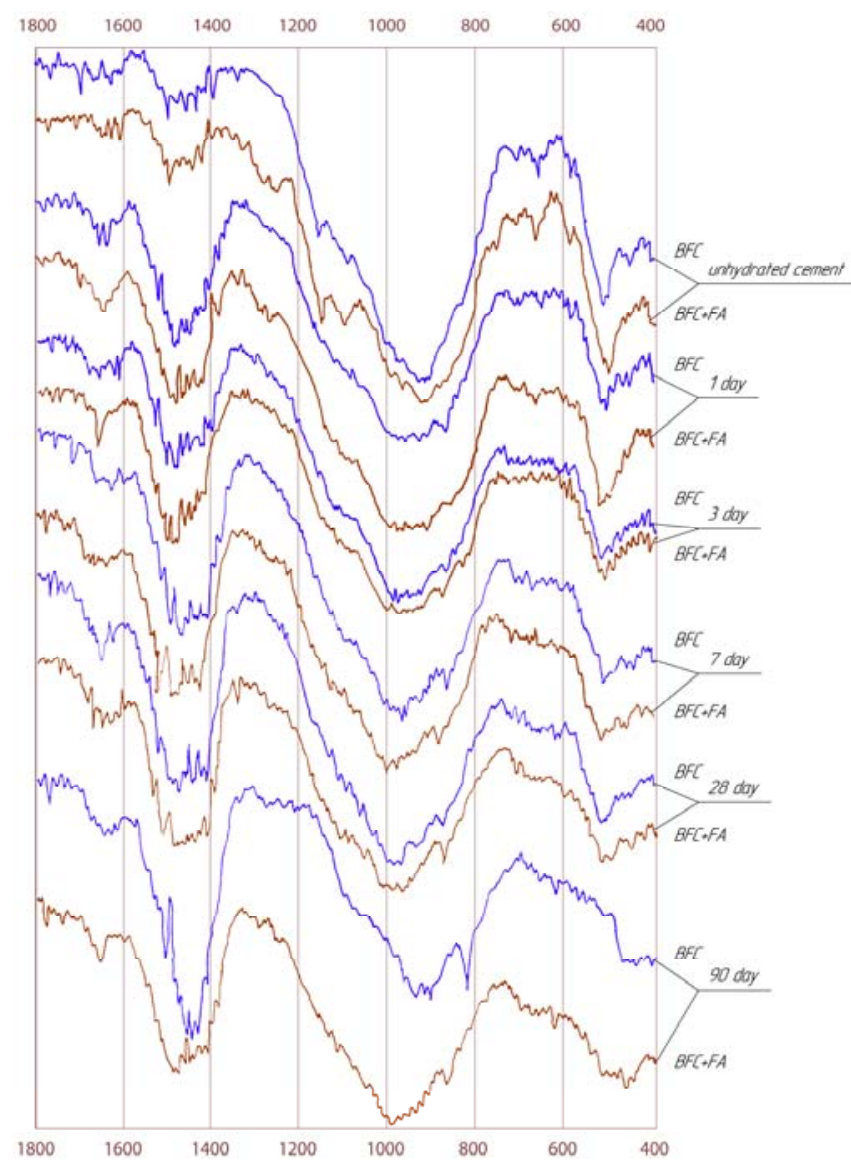

Fig. 1. Infrared absorption spectra of samples from the blastfurnace cement (BFC) and blast-furnace cement with a ferromagnetic additive (BFC+FA) in the initial state and age 1, $3,7,28$, and 90 days.

When calcium aluminates are hydrated, $\mathrm{CAN}_{6}$ is formed, identified on DTA (Fig. 3) by endothermic effects at $330-350{ }^{\circ} \mathrm{C}$ and $530-570{ }^{\circ} \mathrm{C}$.

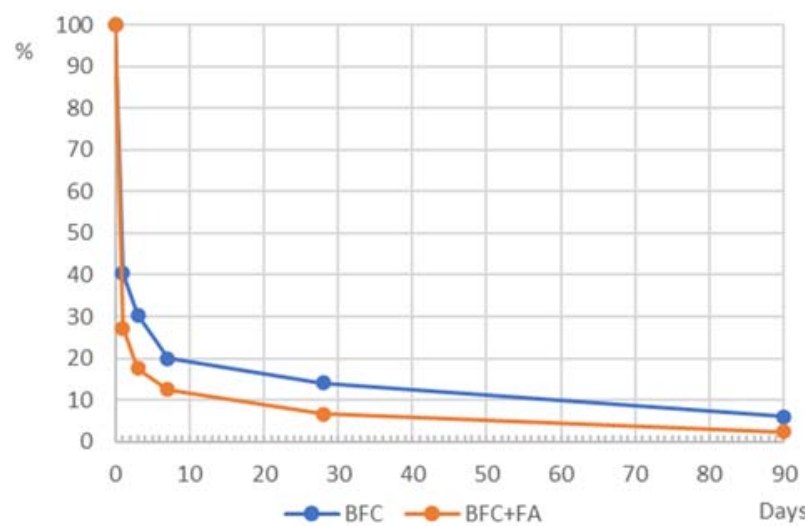

Fig. 2. Kinetics of hydration of calcium aluminates.

The significantly immense value of the cement stone's effects from the modified binder indicates the activating effect of magnetic fields on the process of formation of tricalcium aluminate hexahydrate.

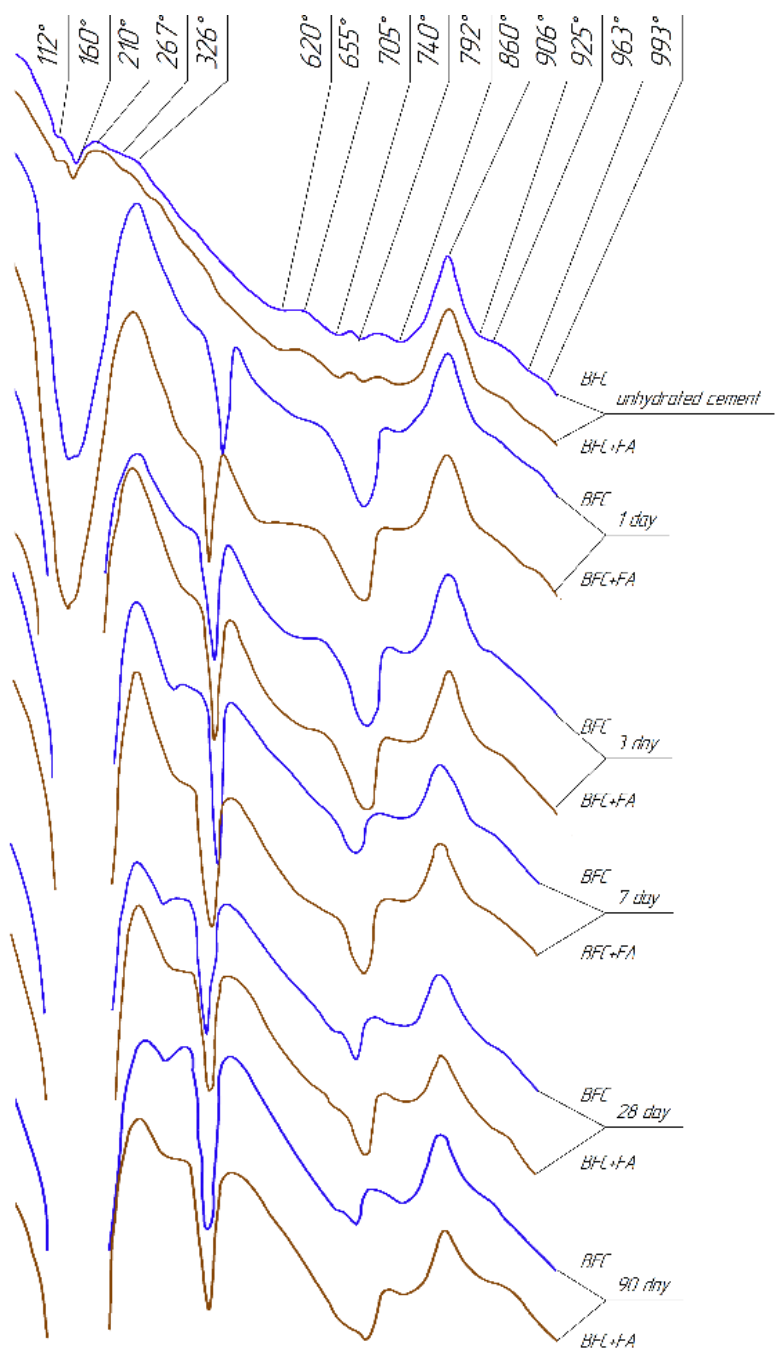

Fig. 3. Curves of differential thermal analysis of samples from the blast-furnace cement (BFC) and blast-furnace cement with a ferromagnetic additive $(\mathrm{BFC}+\mathrm{FA})$ in the initial state and age $1,3,7,28$, and 90 days.

At the age of 1 day on DTG (Fig. 4) of the modified cement stone, the effect is more pronounced at 140$200{ }^{\circ} \mathrm{C}$. In subsequent periods, the intensity of the effects of both types of binders leveled. An increase in the IR spectrum with $\mathrm{C}=1630 \mathrm{~cm}^{-1}$ at IR occurs synchronously.

The data indicate the intensive formation of ettringite under the influence of a ferromagnetic additive in up to 1 day and the termination of this process subsequent periods. In a standard binder, ettringite formation observes up to the age of 3 days.

The observed dynamics of the formation of calcium hydro-aluminates and calcium hydro-sulfa-aluminates allow us to conclude that, under the influence of the additive's magnetic fields, constructing the gel's ettringite framework occurs faster and completed within one day. In the subsequent periods, stable six-water tricalcium aluminate mainly formed. This mechanism excludes destructive processes in the late stages of hydration.

The kinetics of hydration of blast-furnace cement is determined by the lime-releasing clinker component - 
alite. Acceleration of alite hydration increases calcium hydroxide concentration and intensifies hydration of granulated blast-furnace slag. On the X-ray diffraction patterns (Fig. 5), the process of alite hydration is indicated by a decrease in the height of the peaks with $\mathrm{d}=0.295$; $0.321 ; 0.327 ; 0.519 \mathrm{~nm}$.

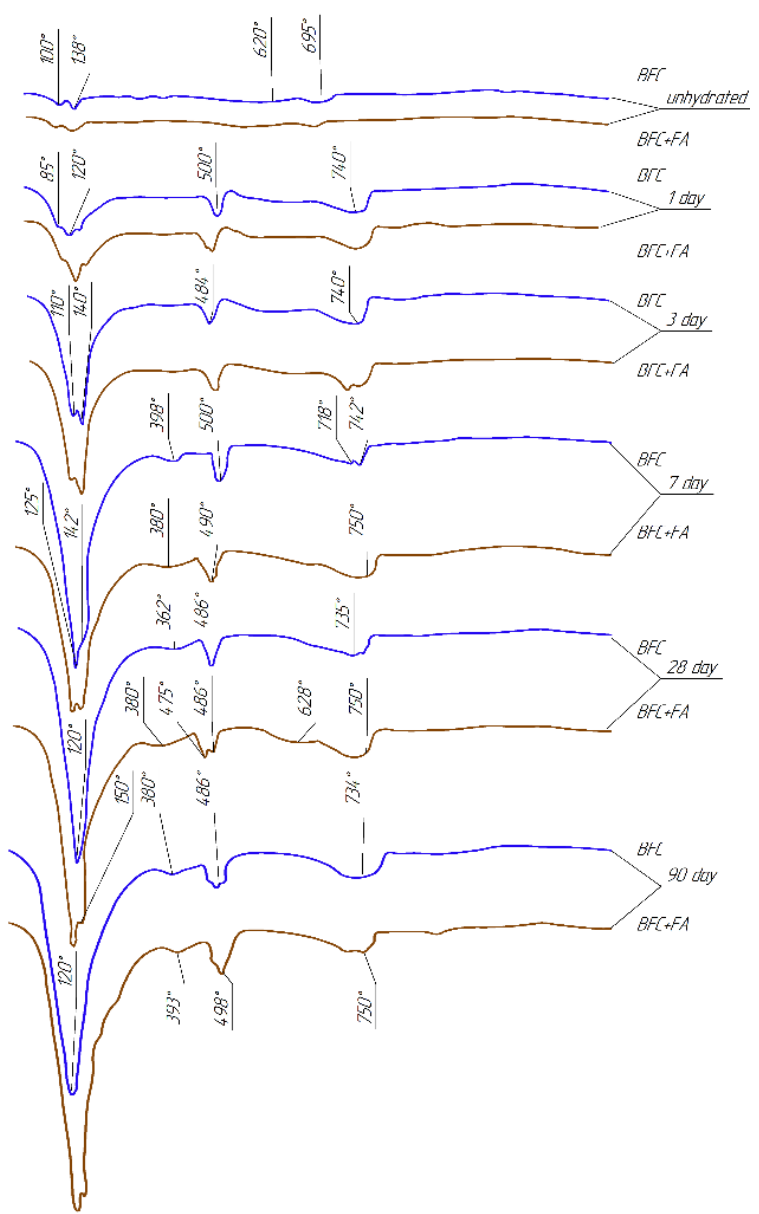

Fig. 4. Curves of differential thermogravimetric analysis of blast-furnace cement (BFC) and blast-furnace cement with a ferromagnetic additive (BFC+FA) in the initial state and age 1, $3,7,28$, and 90 days.

A decrease in the bands' absorption intensity with $\mathrm{C}=992 \mathrm{~cm}^{-1}$ was observed simultaneously at $875 \mathrm{~cm}^{-1}$ in IR spectrograms. The results showed that the kinetics of alite hydration in the modified binder significantly differs from the usual one. At the age of 1-3 days, 13-8\% less is hydrated, and at the period of 7-90 days, 4-5 times the amount of alite is hydrated (Fig. 6).

The slowdown in the hydration of alite at the age of 13 days can be explained only by the reaction space's supersaturation with calcium hydroxide and the chemical reaction shift $2 \mathrm{Ca}_{3} \mathrm{SiO}_{5}+6 \mathrm{H}_{2} \mathrm{O}=\mathrm{Ca}_{3} \mathrm{SiO}_{7} \cdot 3 \mathrm{H}_{2} \mathrm{O}+3 \mathrm{Ca}(\mathrm{OH})_{2}$ towards initial components. The intensive hydration of alite causes an increase in $\mathrm{Ca}(\mathrm{OH})_{2}$ in the period up to the first day. The magnetic fields induced by the ferromagnetic additive cannot influence the diffusion rate of the reaction products. Therefore, in the modified binder, the limiting factor of alite hydration is much faster than in the usual one, diffusion from the $\mathrm{Ca}^{2+}$ reaction zone becomes.

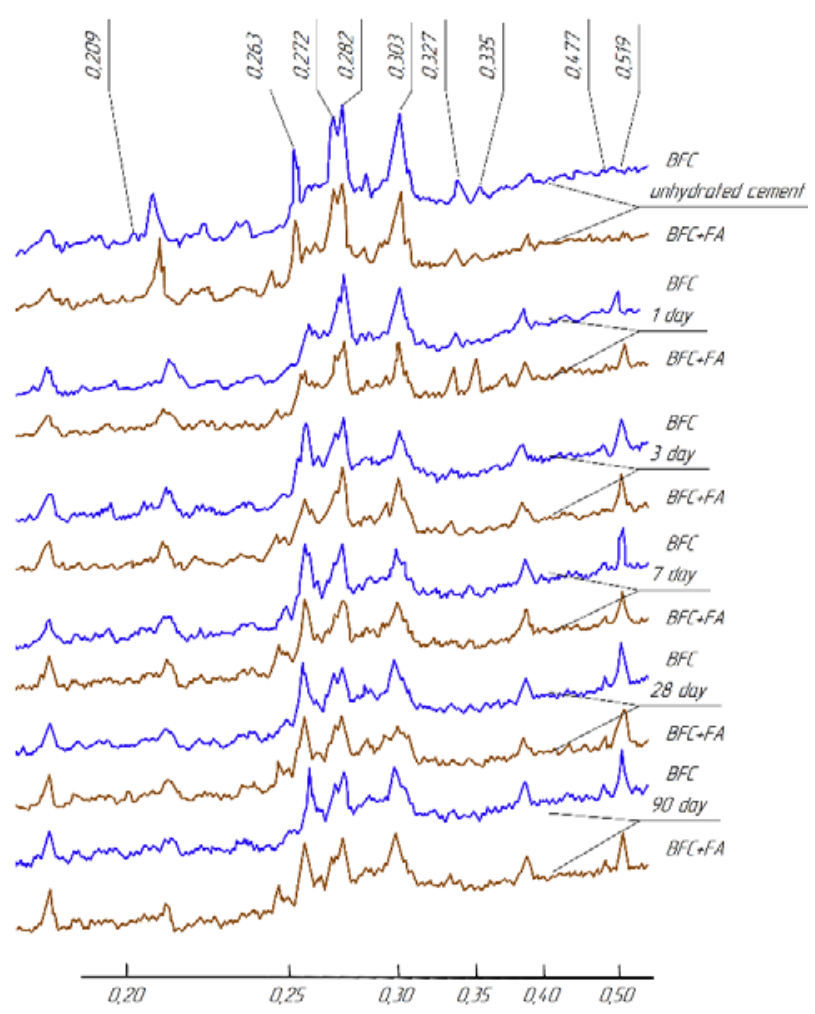

Fig. 5. X-ray patterns of samples from the blast-furnace cement (BFC) and blast-furnace cement with a ferromagnetic additive $(\mathrm{BFC}+\mathrm{FA})$ in the initial state and age of $1,3,7,28$, and 90 days.

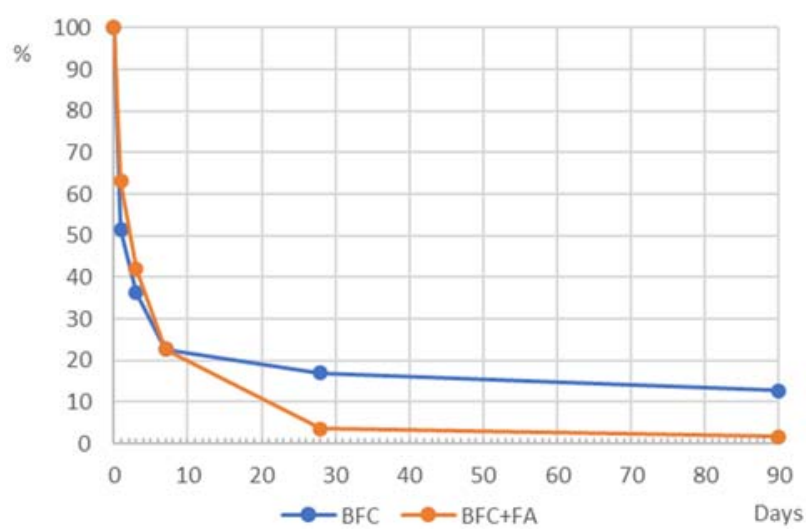

Fig. 6. Kinetics hydration of alit.

An increase in the amount of lime in the gel corresponds to the rise in the peaks with $d=0.263 ; 0.179$; $0.168 \mathrm{~nm}$ on X-ray diffraction patterns. The strong endothermic effect arising from the dehydration of $\mathrm{Ca}(\mathrm{OH})_{2}$ makes it possible to control its concentration on DTA at $\mathrm{t}=485^{\circ}$. Analysis of the results confirmed the accelerated formation of lime in a period of up to 1 day. (Fig. 7).

In the gel made of modified cement, calcium hydroxide content is $20 \%$ higher than in the control samples during this period. Although in the subsequent period, the alite degree of hydration under the influence of magnetic fields increases, the content of $\mathrm{Ca}(\mathrm{OH})_{2}$ in the gel becomes $23 \%$ lower than in the original cement at the age of 3 days, by $12 \%$ at the period of 7 days and by $9 \%$ in the age of 28 days. Such dynamics can be explained only by intensifying lime interaction with granulated 
blast-furnace slag. In this case, a decrease in the IR spectrum's absorption intensity in the region of $\mathrm{C}=721 \mathrm{~cm}^{-1}$ and a reduction in the exothermic effect of the slag's devitrification $\mathrm{t}=830-870^{\circ} \mathrm{C}$ on DTA due observe. Simultaneously, an increase in the height of the peaks with $\mathrm{C}=648 \mathrm{~cm}^{-1}$ should observe, which characterize the content of the slag hydration product, boehmite, in the gel.

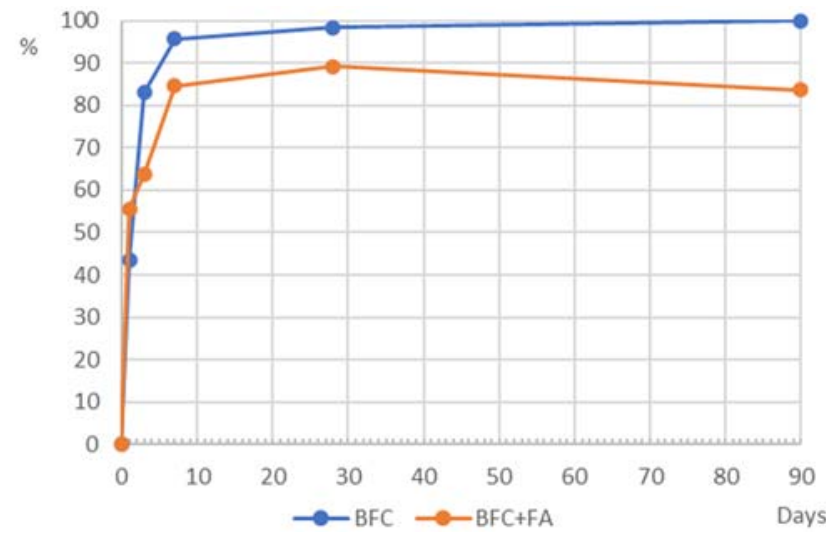

Fig. 7. Kinetics of lime formation.

Analysis of the results confirms that the hydration of granulated blast furnace slag intensified under the action of magnetic fields induced by a ferromagnetic additive (Fig. 8). There is an increase in slag hydration degree by $20 \%$ at three days, $23 \%$ at 28 days, and $59 \%$ at 90 days.

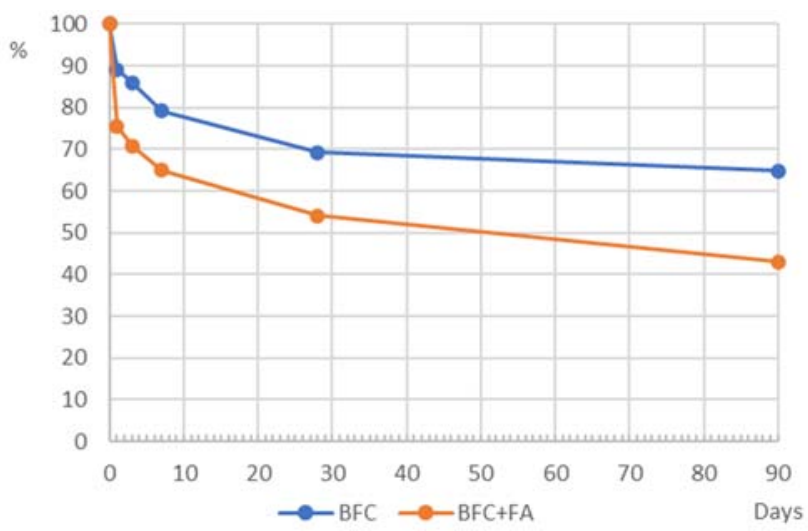

Fig. 8. Slag hydration kinetics.

In ordinary cement, after 28 days of hydration, the slag content practically does not change. In the same period, the content of slag in the modified binder decreases by $30 \%$. A decrease in the non-hydrated slag content corresponds to an increase in the amount of boehmite in the cement gel (Fig. 9).

In the control cement, boehmite was identified only after three days of hydration, while in the modified binder, characteristic peaks were clearly defined after hydration for one day. Like slag hydration, the process of boehmite formation in the control binder practically stops after 28 days of hardening. On the contrary, long-term continuous exposure to magnetic fields on the modified binder maintains high slag hydration rates later.

In the period 28-90 days, the content of alite in the modified binder is insignificant and amounts to $4-2 \%$ of the original. Such content of $\mathrm{C}_{3} \mathrm{~S}$ does not provide the slag's hydration with a sufficient amount of calcium hydroxide. The slag's intensive hardening proceeds due to the binding of $\mathrm{Ca}(\mathrm{OH})_{2}$ previously formed reserves. This process reduces the lime content in the modified cement stone of 90 days of age by $65 \%$ (Fig. 7).

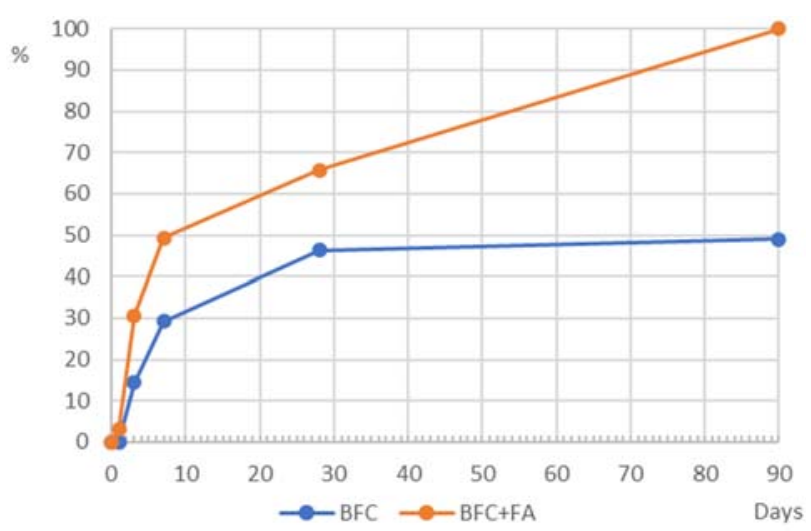

Fig. 9. Kinetics of boehmite formation.

The kinetics of cement stone's carbonization has confirmed a ferromagnetic additive's peculiarities on alite and slag's hydration processes. $\mathrm{CaCO}_{3}$ has pronounced peaks with $\mathrm{d}=0.303 ; 0.249 ; 0.228 ; 0.209 \mathrm{~nm}$ on X-ray diffraction patterns and an absorption band of IR radiation with $\mathrm{C}=1500-1400 \mathrm{~cm}^{-1}$. Calcite gives a noticeable endothermic effect at $\mathrm{t}=740{ }^{\circ} \mathrm{C}$ on DTA. However, due to the intensive carbonization of lime with carbon dioxide in the furnace atmosphere during heating of the sample, the concentration of $\mathrm{CaCO}_{3}$ overestimated compared to other methods was obtained on DTA.

Analysis of the data obtained shows a correlation between calcium carbonate content and $\mathrm{Ca}(\mathrm{OH})_{2}$. At the age of 1 day in the gel of modified binder calcite by $50 \%$ more than in control one (Fig. 10).

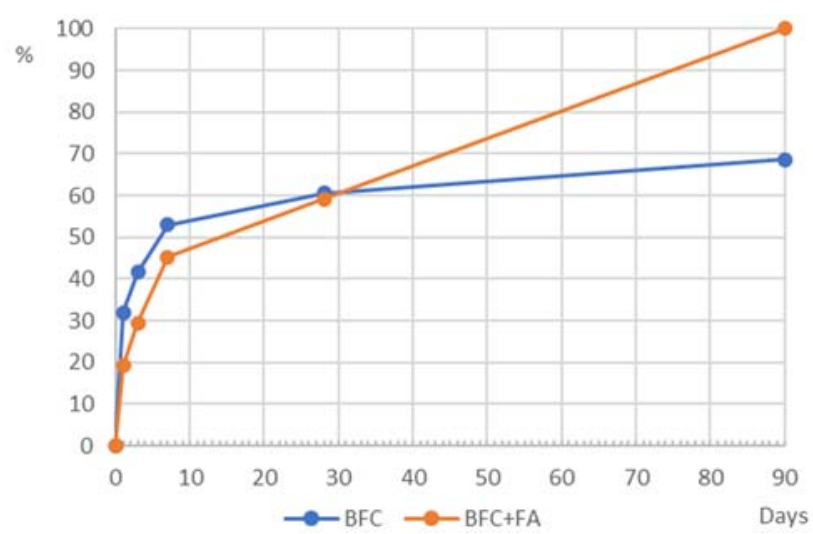

Fig. 10. Kinetics of calcite formation.

During the first ten days, the rate of lime binding with 100 grams of slag is 0.3 grams per day, from 10 to 40 days $-0.1 \mathrm{~g} /$ day, and in the period from 40 to 90 days, 0.05 $\mathrm{g} /$ day [20]. A continuous decrease in lime absorption by slag with continuous hydration of alite in conventional cement types leads to the accumulation of $\mathrm{Ca}(\mathrm{OH})_{2}$ and, due to carbonization, to increase the $\mathrm{CaCO}_{3}$ content. The accelerated release of lime in the modified binder increases the calcium carbonate content at the initial time. A higher, under the influence of magnetic fields, the rate 
of lime absorption by slag decreases after 28 days of hydration $\mathrm{Ca}(\mathrm{OH})_{2}$ and "freezes" the concentration of $\mathrm{CaCO}_{3}$.

At the age of 28 days in the modified gel of calcium carbonate, only $5 \%$ more than in the control one. In the control binder, a low rate of lime binding with slag in 2890 days leads to an increase in the content of calcium carbonate by $58 \%$. Over the same period, the modified binder's lime content decreases by $6 \%$, with an increase in the $\mathrm{CaCO}_{3}$ content only by $10 \%$.

The considered features of the ferromagnetic additive effect on the alite-lime-slag system's hydration allow us to assume the ambiguity of the impact of the modified binder's heat and moisture treatment. In the initial periods of hardening, magnetic fields increase the difference in the lime release rate by alite and its absorption by slag. Heat treatment, increasing the rate of chemical reactions, can further enhance this phenomenon. The excessive rate of hydration products' release increases the unevenness of their distribution in the cement stone, causing destructive processes. Based on this, the combined effect of magnetic and thermal fields can lead to a drop in the cement stone's strength. It is possible to increase the modified binder's tolerance to heat and moisture treatment by expanding its slag. The increased absorption of lime thus promotes the formation of a more stable calcium silicate hydrate.

The revealed patterns make it possible to explain the greater efficiency of magnetic activation for belite types of cement. A smaller amount of lime released during the hardening of belite makes this process less dependent on diffusion. Therefore, the formation process in belite cement under the influence of magnetic fields should be more stable.

Belite hydration is characterized by a decrease in the intensity of peaks with $\mathrm{d}=0.282 ; 0.272 ; 0.269 ; 0.266 \mathrm{~nm}$ on X-ray diffraction patterns and a decrease in the intensity of absorption of IR radiation with $\mathrm{C}=900$; $963 \mathrm{~cm}^{-1}$. The analysis results show that the ferromagnetic additive has an intensifying effect on the process of belite hydration (Fig. 11). The content of non-hydrated belite in the modified binder is less than in control one at the age of 1 day by $12 \%, 28$ days by $10 \%$, and at a period of 90 days by $19 \%$. According to [20], in ordinary cement, the hydration of belite, even after four years of hardening, is only $85 \%$. According to the analysis data, in the modified binder, already at the age of 90 days, almost all of the belite is hydrated.

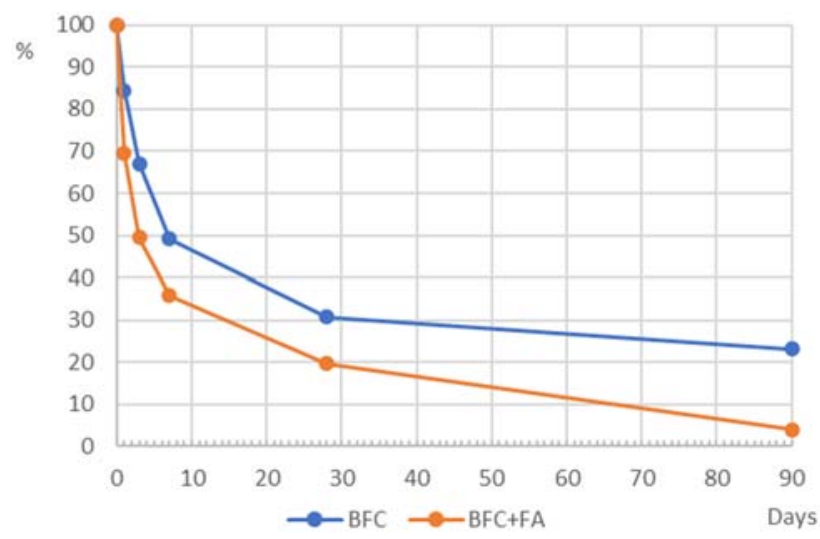

Fig. 11. Kinetics of belite hydration.
Simultaneously with the hydration of belite, there is an increase in peaks $\mathrm{d}=0.477,0.335,0.292 \mathrm{~nm}$, which on the $\mathrm{X}$-ray diffraction patterns correspond to the crystal lattice of hillebrandite. The performed quantitative analysis shows that introducing a ferromagnetic additive into the binder's composition increases hillebrandite content in cement stone of any age approximately twofold (Fig. 12).

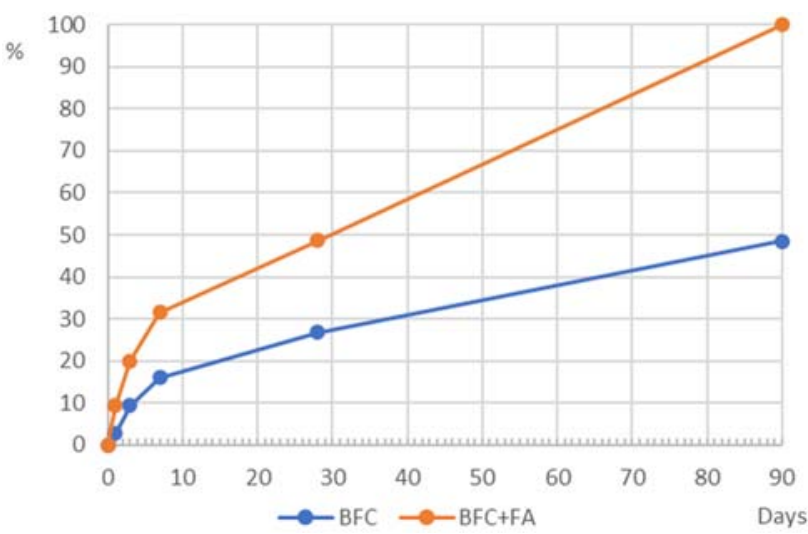

Fig. 12. Kinetics of hillebrandite formation.

The absence of intersections of the lines of the conventional and modified binder on the graph of belite hydration and the chart of hillebrandite formation indicates the monotonicity of the process of belite hydration in the presence of magnetic fields and suggests the absence of malicious processes during their heat and moisture treatment in modified belite binders.

Infrared spectrometry data confirm the results obtained. Silicates have a characteristic infrared absorption band in the $1100-500 \mathrm{~cm}^{-1}$ regions. When the binder is hydrated, the region of the most significant absorption of IR radiation is shifted towards higher frequencies, which corresponds to more potent and more rigid bonds in the hydro silicate. The displacement to the high-frequency regions occurs earlier and manifests more intensively on the modified binder's spectrograms. Analysis of the absorption intensity of IR spectra in the range of $1050-800 \mathrm{~cm}^{-1}$ made it possible to complete the picture of the structure formation of the silicate phase. Clinker and slag minerals with a chain structure characterized by intense absorption of IR radiation range from 1030-800 $\mathrm{cm}^{-1}$. Research results show a higher degree of silicates' hydration at all hardening stages (Fig. 13). At the age of 3 days, the original silicates in the modified binder are 1.5 times less; at 28 days by 2.5 times, at a period of 90 days by four times. The gel's oversaturation with calcium hydroxide and the slowdown in the hydration of alite explain the change's nonmonotonicity in silicates hydration rate in up to 7 days.

The range of 1020-990 $\mathrm{cm}^{-1}$ is typical for silicates with a network structure. The spectrograms under consideration allow one to determine the content of crystallized tobermorite in the cement stone (Fig. 14). Analysis of the results shows that the ferromagnetic additive, changing the kinetics of hydration reactions, contributes to increasing the crystallized tobermorite content in cement stone by 1.3-1.4 times.

The transition of hydro silicates from a weakly crystallized to a crystallized state changes the amount of 
adsorbed water. On thermograms, this process accompanying a decrease in the endothermic effect at 60$200{ }^{\circ} \mathrm{C}$. Analysis of the areas of endothermic effects on DTA and mass losses on DTG in this temperature range shows a change in the interlayer liquid forming dynamics (Fig. 15).

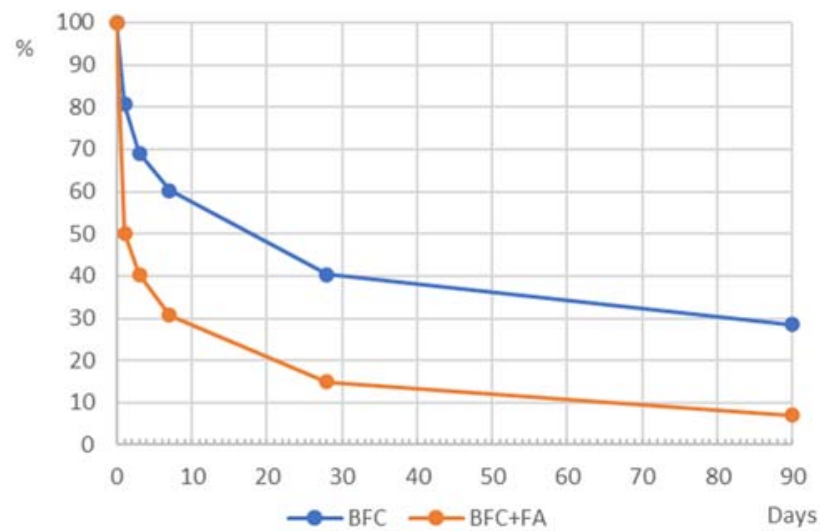

Fig. 13. Hydration kinetics of chain calcium silicates.

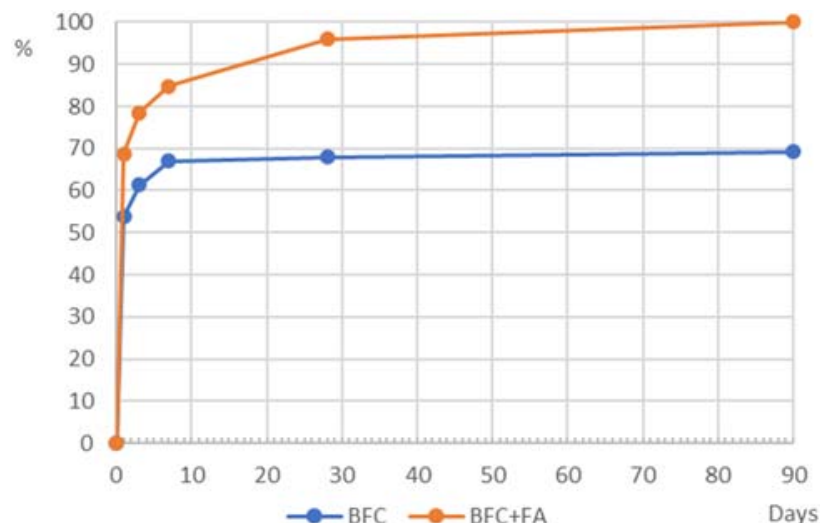

Fig. 14. Kinetics of crystallized tobermorite formation.

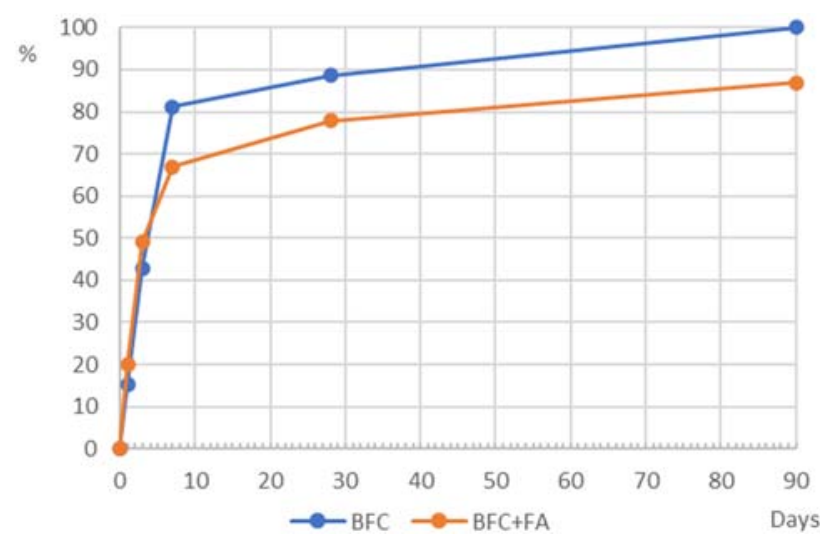

Fig. 15. Kinetics of formation of interlayer water.

The modified binder at the age of 0-3 days has a 5$10 \%$ more, and in subsequent periods, $15-20 \%$ less adsorbed water. Such a change in the binding dynamics of water confirms an increase in $\mathrm{CSH}$ formation in the initial period and a higher rate of construction of hydro silicates' crystallization structure in the subsequent period. Caused by the slag's active hydration, the cement gel's lack of calcium hydroxide contributes to forming a larger number of three-layer tobermorite [20], having a lower specific surface area than two-layer ones and adsorbing a smaller amount of water.

Accelerating the crystallization of tobermorite changes the structure of the cement stone. In Fig. 16 and Fig. 17, the cement stone structures spall from the control and modified binder. Lamellar blocks of crystallized tobermorite dominate the modified cement stone. The structure of the modified cement stone is more homogeneous and finer crystalline.

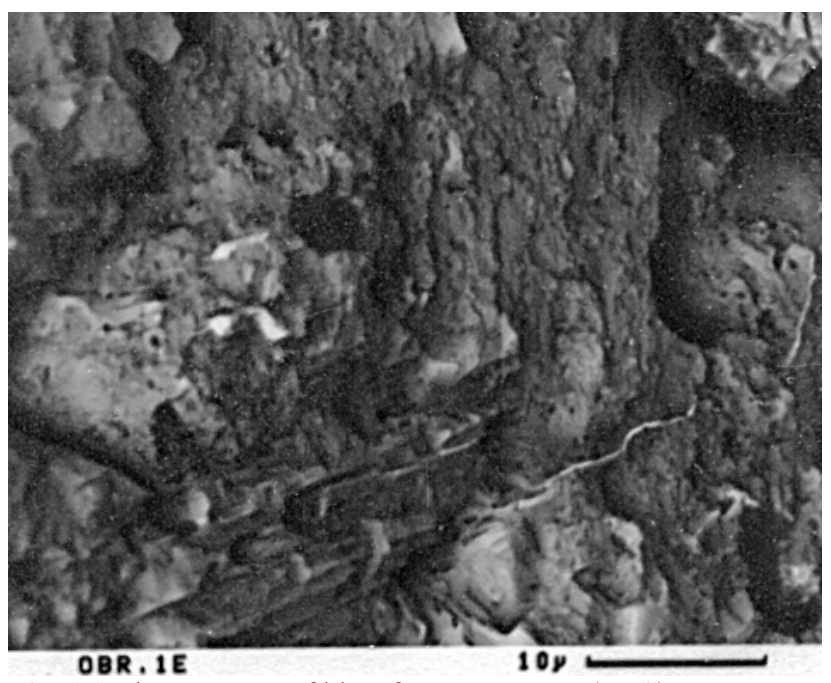

Fig. 16. The structure of blast furnace cement (BFC).

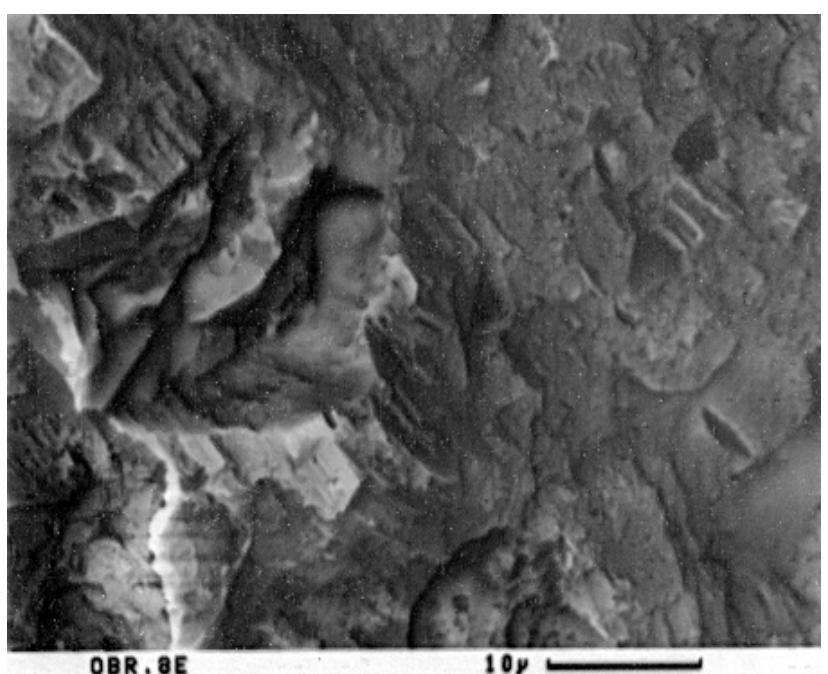

Fig. 17. Structure of cement stone from blast furnace cement with ferromagnetic additive (BFC+FA).

In [21], the orienting effect of magnetic fields on colloidal particles is noting. This phenomenon promotes crystallization and the formation of uniformly oriented crystal structures. The uniform spatial orientation of tobermorite plates observed in the modified cement stone confirms the hydrogel's magnetic fields' orienting effect. The images obtained at $8000 \times$ magnification (Fig. 18, 19, and 20) confirm a crystalline structure in the modified cement stone and a weakly crystallized, disordered structure in the control cement stone.

A photograph was taken in the phase contrasts mode (Fig. 19), making it possible to isolate a magnetized dust particle with a darker shade. The "ingrowth" of dust particles into the binder structure is noticeable. 


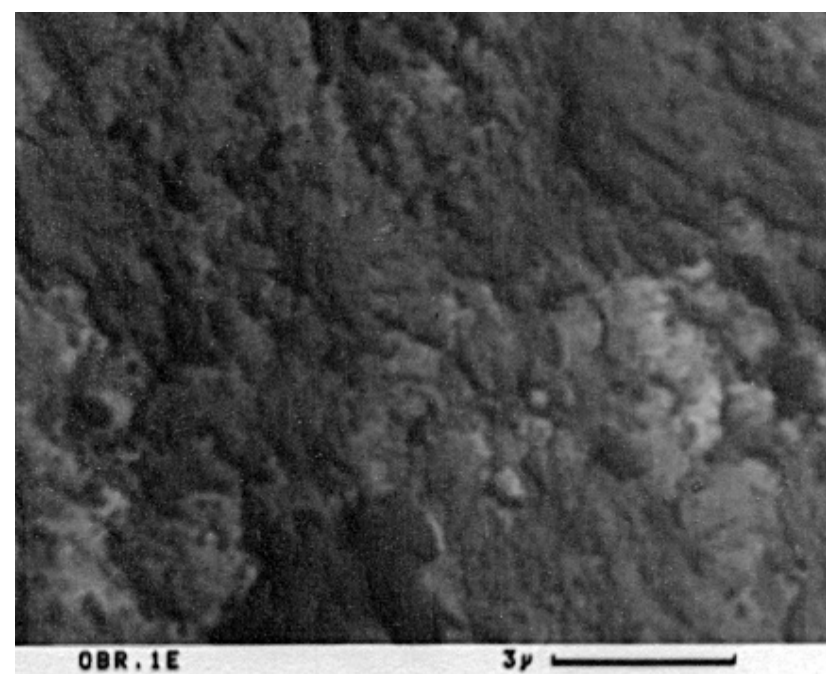

Fig. 18. Structure of blast-furnace cement (BFC).

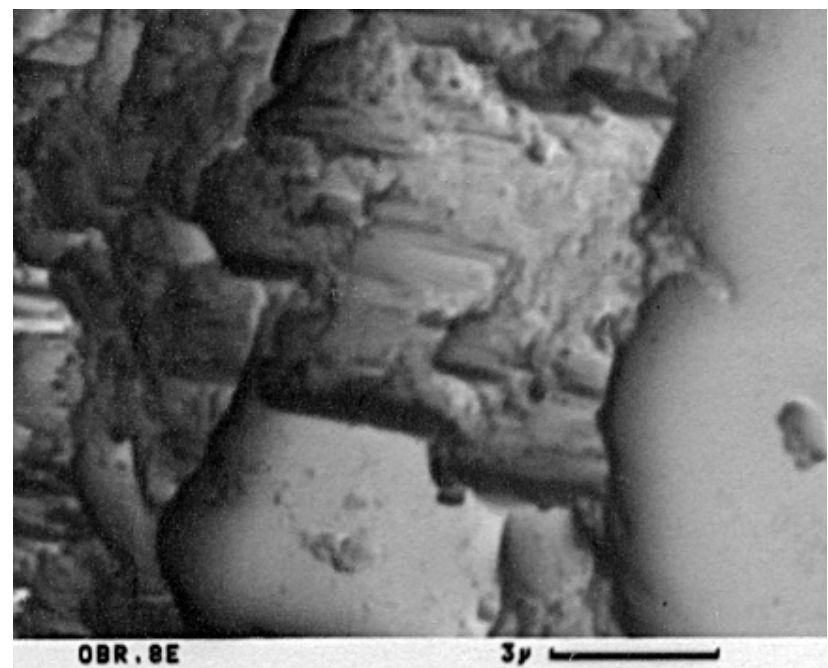

Fig. 19. Structure of cement stone from blast-furnace cement with ferromagnetic additive $(\mathrm{BFC}+\mathrm{FA})$.

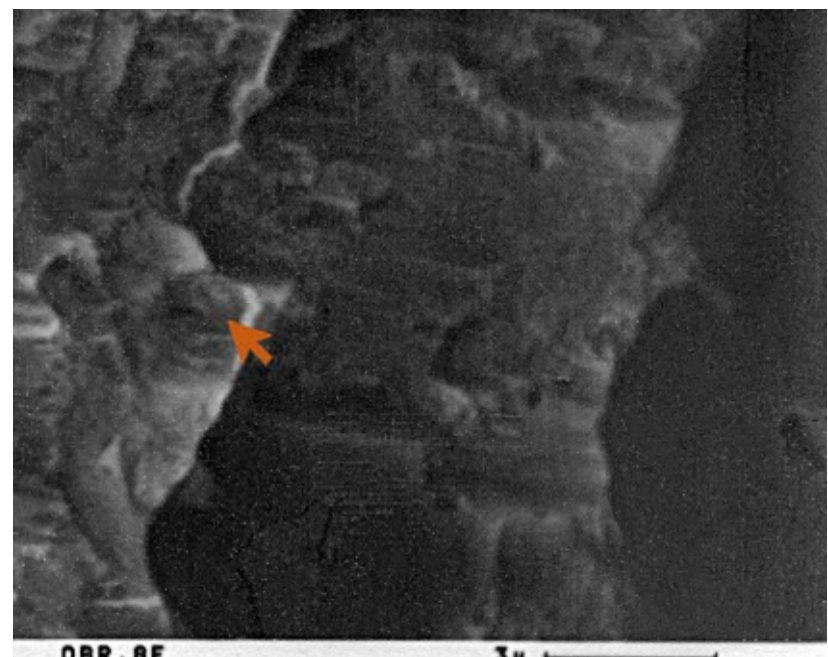

OBR, BE

3y

Fig. 20. Structure of a cement stone made of blast-furnace cement with a ferromagnetic additive $(\mathrm{BFC}+\mathrm{FA})$. Phasecontrast mode. The arrow marks an ingrown dust particle.

A high degree of hydration of the modified binder reduces the proportion of evaporated mixing water, reducing the cement stone's overall porosity. Fig. 21 shows the surface of a cement stone spall from a nonactivated BFC. Numerous microcracks with a length of 50-200 $\mu$ and a thickness of $0.5-1 \mu$ are distinguishable on the surface. Microcracks are oriented in different directions and, as a rule, begin at micropores. Numerous micropores are 2-30 $\mu$ in size.

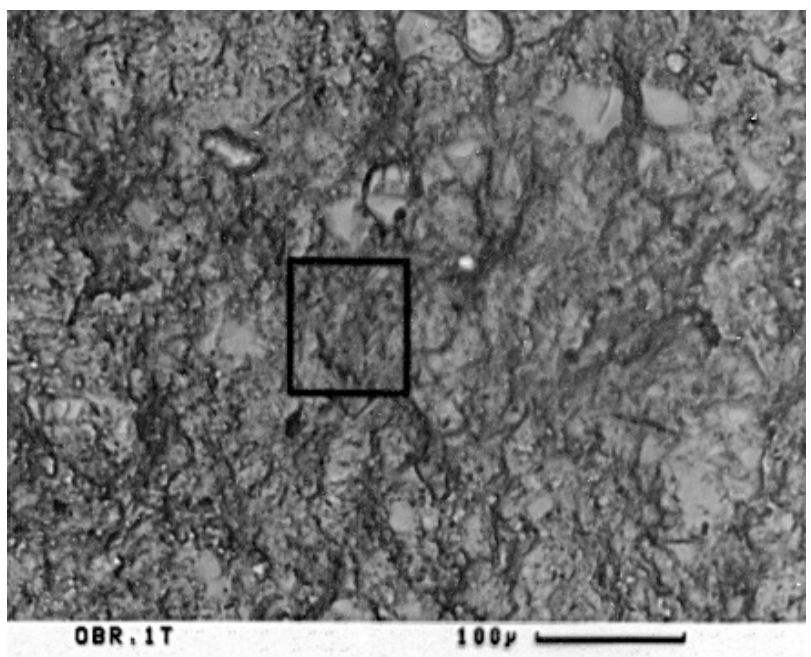

Fig. 21. Structure of blast-furnace cement (BFC).

A smaller number of structural defects distinguishes a cement stone made from a modified binder (Fig. 22, 23). A small number of pores with a size of $0.5-2 \mu$ and the absence of broader.

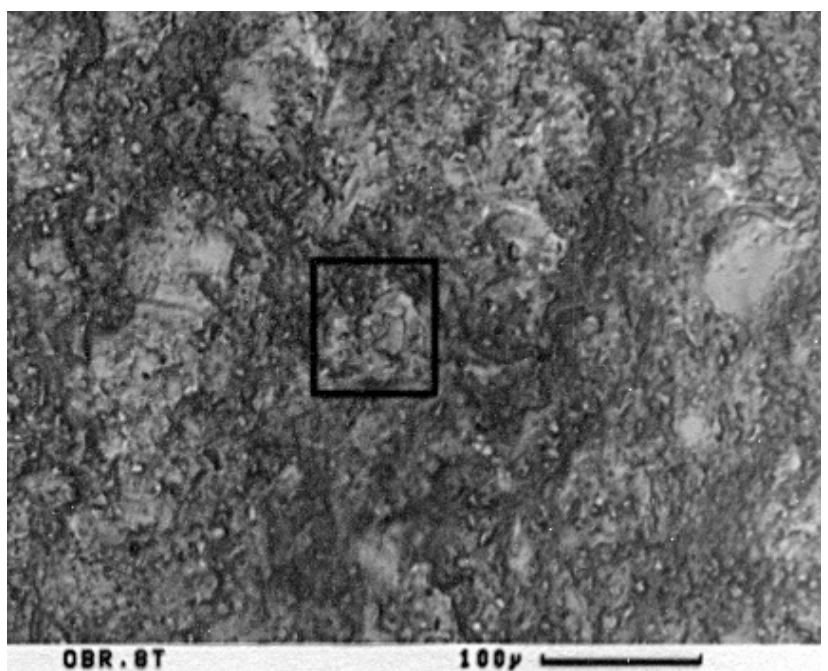

Fig. 22. Structure of cement stone from blast-furnace cement with ferromagnetic additive (BFC+FA).

A decrease in the porosity of a cement stone can be caused by factors other than magnetic fields. A cement stone structure from a binder with a reduced $(0.75 \%)$ ferromagnetic additive content was investigated to test this factor's significance. With the microprobe's help, a dust particle was found, and the microstructure in the area adjacent to it was investigated. In the images obtained in the relief mode (Fig. 24) and phase contrasts (Fig. 25), a decrease in the cement stone porosity is observed as the dust particle approaches and the magnetic field strength increases. This confirms the magnetic field strength's 
influence on the degree of hydration of the binder and the cement stone's porosity.

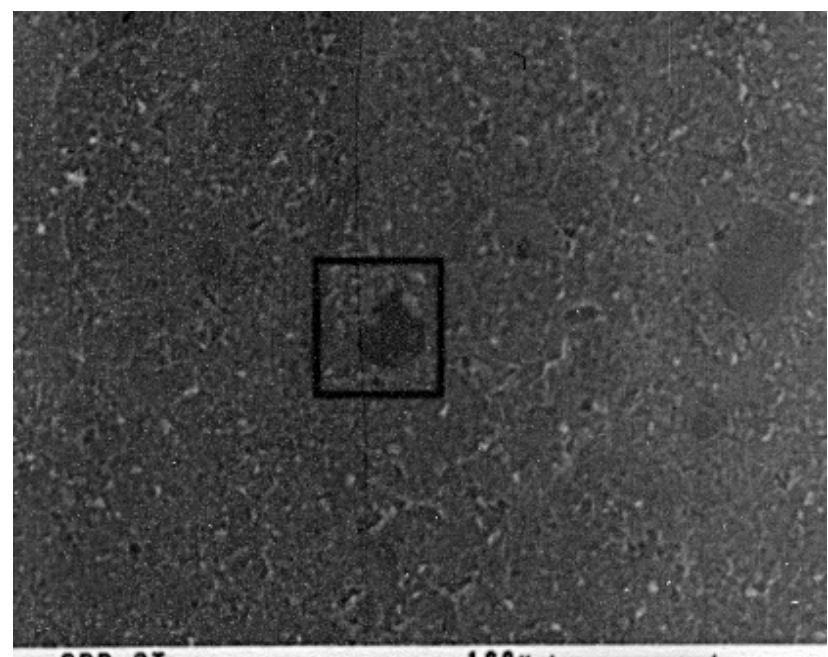

OBR, 8T

$100 y$

Fig. 23. Structure of cement stone from blast-furnace cement with ferromagnetic additive $(\mathrm{BFC}+\mathrm{FA})$ Phase-contrast mode.

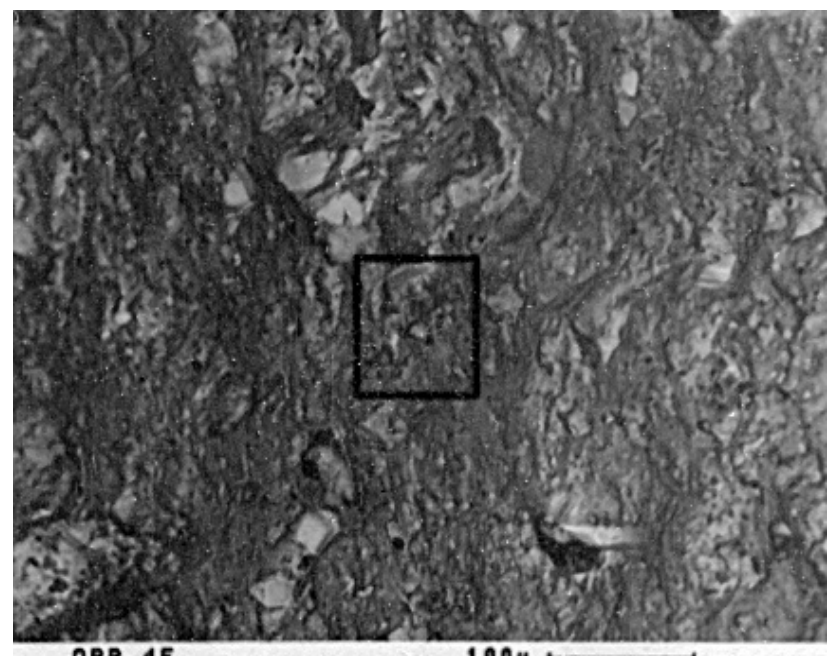

OBR, 4E

$100 y$

Fig. 24. Structure of cement stone from blast-furnace cement with ferromagnetic additive (BFC+FA).

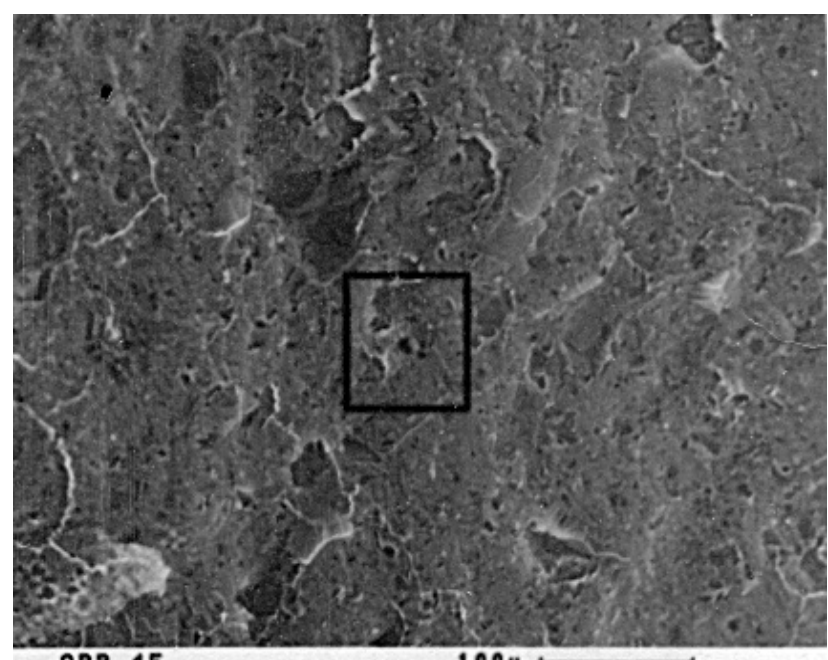

OBR, 4E

1004

Fig. 25. Structure of cement stone from blast-furnace cement with ferromagnetic additive $(\mathrm{BFC}+\mathrm{FA})$ Phase-contrast mode.

\section{Conclusions}

The studies show that the introduction of pre-magnetized ferromagnetic dust into blast furnace cement composition has an activating effect on binder hydration. Activation occurs both in the initial and long periods of hardening. The additive influence on the process of structure formation at a specific point of the cement gel depends on the distance between this point and the dust particle and the magnetic fields' intensity at this point.

It proved that under the influence of magnetic fields, intensive hydration of alite in up to 1 day causes supersaturation of the gel with calcium hydroxide, which slows down the hydration of alite for a period of up to 7 days. We found that the second increase in the hydration rate of alite after seven days of age is caused by the intensive, under the additive, absorption of lime by slag. It determined that the ferromagnetic additive, intensifying the process of slag hardening, increases the proportion of hydrated slag by 1.5-2 times.

The investigation established that the reduced release of lime during hardening determines the monotony of the increase in the rate of hydration of belite in the modified binder. It determined that the most significant activating effect on $\mathrm{C}_{2} \mathrm{~S}$ hydration be achieved after 28 days of hardening.

Studies proved that the ettringite framework's formation in the modified binder's gel is completed within one day. In subsequent periods, the hydration of aluminates occurs mainly due to the formation of tricalcium aluminate hexahydrate, which excludes destructive processes in the late periods of binder hardening.

It founded that under the impact of a ferromagnetic additive, the crystallization of hydro silicates in the modified binder increases. It determined that magnetic fields have an orienting effect on the direction of hydro silicate crystals' growth, which leads to a decrease in the porosity and defectiveness of the cement stone structure.

\section{References}

1. U.S. Geological Survey: Mineral Commodity Summaries 2020. U.S. Geological Survey (2020)

2. Sanytsky, M., Kropyvnytska, T., Fic, S., Ivashchyshyn, H. Sustainable low-carbon binders and concretes. E3S Web of Conferences, (2020), 166, 06007

3. International Energy Agency: Technology Roadmap. Low -Carbon Transition in the Cement Industry. World Business Council for Sustainable Development (2018)

4. Trofimov, B., Kramar, L., Shuldyakov, K.: Influence of Slag Quantity in Cement on Frost - Resistance of Heavy -Weight Concrete. Stroitel'nye Materialy. 9, 96 (2013)

5. Buchachenko, A.: Second generation of magnetic effects in chemical reactions. Russ. Chem. 62, 1139 (1993) 
6. Lapcik, L., Simek, Z.: Electron paramagnetic resonance study of dry cements. Cem. Concr. Res. 26(2), 237 (1996).

7. E. Lopanova, E.: Radiospectroscopic researches of process of hydration of silicates with the help of spin labels. Voprosy Materialovedeniya. 3, 34 (2004).

8. Afanas'ev, D., Tsyro, L., Unger, A., Andreeva, L., Alexandrova, S., Afanas'ev, D.: Spin aspects in the nature of cement hardening. Polzunovsky Vestnik, 3, 82 (2009).

9. Afanas'ev, D., Tsyro, L., Unger, A., Andreeva, L., Alexandrova, S., Unger, F.: Unger, Spin chemistry of cement systems. Vestnik nauki sibiry. 5, 247 (2012).

10. Afanas'ev, D., Unger, F., Tsyro, L., Sarkisov, Y., Gorlenco, N.: The role of spin effects in structure formation of cement mixtures. Vestnik TGASU, 2, 94 (2014).

11. Sakhno, S., Yanova, L., Pischikova, O.: Application of sintering dust for the increase of cement durability. Innovative Development of Resource-Saving Technologies of Mineral Mining and Processing. pp. 124 -126. UNIVERSITAS Publishing, Petroșani, Romania (2018)

12. Sakhno, S., Yanova, L., Pischikova, O.: Study of the influence of properties of dusty ferromagnetic additives on the increase of cement activity. E3S Web of Conferences. (2020), 166, 06002.

13. Salikhov, K., Molin, Y., Sagdeev, R., Buchachenko, A. and Molin, Y.: Spin Polarization and Magnetic Effects in Radical Reactions. Amstrerdam: Elsevier; Budapest: Akademiai Kiado. (1984).

14. Susak, I.: The Effect Of Magnetic Fields On The Physicochemical Properties Of Molecular Fluids And Biological Systems, (2003).

15. Su, N., Wu, Y.,H., Mar, C.,Y.: Effect of magnetic water on the engineering properties of concrete containing granulated blast-furnace slag. Cem Concr Res. 20 599-605 (2000). doi:10.1016/S00088846(00)00215-5.

16. Gorlenko, N.P., Safronov, V.N., Abzaev, Y.A., Sarkisov, Y.S., Kugaevskaya, S.N., Ermilova, T.A.: Magnetic field as factor of control for structure and properties of cement systems. Vestnik TGASU. 3, 134-150 (2015).

17. Gorlenko, N.P., Kulinich, E.A., Alesina, N.V., Sarkisov, Yu.S.: Aktiviruyushchee vozdeistvie magnitnogo polya na protsessy strukturoobrazovaniya dispersnykh sistem [Magnetic activation effect on structure formation of dispersion systems]. Vestnik TSUAB. 1, 5-8 (2001).

18. Safronov, V.N., Gorlenko, N.P., Sarkisov, Yu.S., Abzaev, Yu.A., Kugaevskaya, S.A., Ermilova T.A.: Rol' tsiklovoi magnitnoi obrabotki vody zatvoreniya $\mathrm{v}$ upravlenii svoistvami i protsessami gidratatsii $\mathrm{i}$ strukturoobrazovaniya tsementnykh sistem [Mixing water magnetic activation cycle effect on hydration and structure formation of cement systems] Vestnik TSUAB. 4. 135-148 (2014).
19. Selyaev, V., Kolotushkin, V.: Influence of technological modes of magnetic activasion on elastic strength characteristics of cement composites. Regional Architecture and Engineering. 2(27), 17 (2016).

20. Taylor, H.: Cement chemistry. Thomas Telford Ltd., London (2009).

21. Parker, M.R., RPAR van Kleef, Myron, H.W., Wyder, P.: Particle aggregation in colloids in high magnetic fields. Journal of Magnetism and Magnetic Materials. Elsevier. (1982). 